\title{
Unir teoría y práctica a través de lo virtual: una innovación docente aplicada al diseño de instalaciones
}

\section{Coupling theory and practice through the virtual: a teaching innovation applied to the design of installations}

CARmen María Calama González

ORCID: https://orcid.org/0000-0002-6511-2885

Universidad de Sevilla. Departamento

Construcciones Arquitectónicas 1 ccalama@us.es

Fecha de recepción: 27-05-2019

Fecha de aceptación: 10-06-2019

DOI: http://dx.doi.org/10.12795/9788447221912.014 Pp.: 336-358 


\section{Resumen}

Este trabajo desarrolla un Ciclo de Mejora en el Aula (CIMA) aplicado a la unidad temática "Agua Caliente Sanitaria" de la asignatura Acondicionamiento e Instalaciones 1, del Grado de Fundamentos de Arquitectura. La alta especialización técnica de la materia, dado su enfoque práctico profesional, deriva con frecuencia en obstáculos de aprendizaje para el alumnado, siendo necesario el planteamiento de una propuesta de mejora docente. Para ello, se plantea una secuencia de actividades didácticas, novedosas frente a la práctica tradicional docente, que permitan al alumnado una participación más activa, el uso de las TICS y ser conscientes de la utilidad de la materia en la resolución de casos reales.

Palabras clave: Acondicionamiento e instalaciones; Grado en Fundamentos de Arquitectura; Docencia universitaria; Experimentación docente universitaria; Ciclo de Mejora en el Aula.

\section{Abstract}

This paper develops a teaching improvement plan for the "Hot Water" thematic unit, taught in the Refurbishment and Installations 1 subject of the Degree in Architecture Fundamentals. The high technical specialisation of this field, given its professional and practical approach, frequently leads to learning obstacles, so it is necessary to propose a teaching improvement practice. To do so, a sequence of educational activities is implemented, through an innovative practice when compared to the traditional focus. This allows students to be more active role, promote the use of the ICTs and be aware of the usefulness of this subject for real cases solution.

Keywords: Refurbishment and Installations; Degree in Architecture Fundamentals; University teaching; University teaching experimentation; Improvement Cycle in Classroom.

Jornadas de Formación e Innovación Docente del Profesorado | № 2 (2019) Esta obra se distribuye con la licencia Creative Commons Reconocimiento-NoComercial-SinObraDerivada 4.0 Internacional (CC BY-NC-ND 4.0.) 


\section{Consideraciones previas. Contexto de la innovación}

El marco de referencia europeo y los cambios sustanciales experimentados en los últimos planes de estudio han fomentado la revisión de las metodologías docentes en busca de herramientas más adecuadas que se adapten a los cambios sociales y capacidades de los estudiantes universitarios del siglo XXI. En este contexto, donde prima la necesidad de una mejor gestión del tiempo, tanto dentro como fuera del aula, parece oportuno plantear formatos de clase más dinámicos en los que docente y estudiantes interactúen, compartiendo la responsabilidad del aprendizaje.

La innovación didáctica presentada en esta comunicación se aplica a la asignatura de Acondicionamiento e Instalaciones 1, impartida en segundo curso del Grado de Fundamentos en Arquitectura de la Universidad de Sevilla, donde la media de estudiantes es de 25 alumnos por clase. Con un desarrollo cuatrimestral (6 ETCS), sigue la estructura más generalizada en el citado grado, con una sesión semanal de dos horas de conocimientos teóricos y dos horas de actividades prácticas. Esta asignatura centra su docencia en el diseño, dimensionado e integración en los edificios de varias instalaciones: protección contra incendios, fontanería, agua caliente sanitaria, saneamiento, ventilación, gas y telecomunicaciones. El objetivo final es la adquisición de competencias para que el estudiante sea capaz de aplicar los conocimientos que se desarrollan en su trabajo profesional, mediante la resolución de problemas, la capacidad para interpretar datos, el razonamiento crítico, la visión espacial o la intuición mecánica. 


\section{Diseño previo del Ciclo de Mejora en el Aula}

\section{Dificultades en el aprendizaje}

En las disciplinas técnicas, los estudiantes deben comprender y asimilar conceptos complejos antes de poder aplicarlos a un proyecto integral. Entre las dificultades a las que se debe hacer frente en esta asignatura, es preciso resaltar el primer contacto del alumnado con la materia a impartir, dada la inexistencia de contenidos afines en los estudios académicos previos. Los conceptos más básicos se convierten en serios obstáculos para el aprendizaje, a lo que hay que añadir el escaso interés del alumnado por asignaturas fundamentalmente técnicas en una carrera en la que prima la creatividad y el diseño, pues, como apunta Francisco Mora (2013), "solo se puede aprender aquello que se ama".

\section{Modelo metodológico y objetivos}

A raíz de las dificultades detectadas, se plantea un modelo metodológico que prime el contenido práctico de la materia, permitiendo al alumnado una involucración más directa en el proceso de aprendizaje, al mismo tiempo que se enfatiza la vinculación última de la materia impartida a la práctica profesional. Se puede sintetizar así:? $\rightarrow T \leftarrow$ $\mathrm{FAQ} \rightarrow \mathrm{P}$

Este modelo se fundamenta en la premisa de conocer las ideas preconcebidas de los estudiantes sobre la materia a impartir (?), de tal forma que, a partir de esas respuestas, pueda plantearse el enfoque teórico más adecuado (T: Teoría). A partir de contenidos teóricos fundamentales, se propone a los estudiantes la resolución de un caso práctico real (P: Práctica), siendo éste el centro neurálgico del método planteado. En este contexto, el alumnado duda y se plantea cuestiones (FAQ: Preguntas frecuentes), siendo necesaria una retroalimentación, de forma escalonada, 
entre teoría-práctica. Con este modelo metodológico, y siendo consciente de los retos planteados y del perfil de los estudiantes, se persiguen los siguientes objetivos:

- Promover prácticas docentes que redunden en la mejora de los procesos de enseñanza-aprendizaje y en los resultados académicos del alumnado.

- Incorporar a la docencia las tecnologías de la información y comunicación, despertando el interés y promoviendo una participación más activa del alumnado.

- Facilitar el desarrollo de las competencias docentes a través de la formación basada en proyectos diseñados, apostando por la participación cooperativa.

- Realizar un seguimiento de la evolución de los estudiantes, evaluando su progresión, las metas alcanzadas y los conocimientos adquiridos.

\section{Mapa de contenidos}

Con vistas a hacer frente a las limitaciones señaladas, resulta necesaria la aplicación de un Ciclo de Mejora en el Aula. Para ello, se ha planteado una propuesta de innovación docente en la unidad temática "Agua Caliente Sanitaria (ACS)", pues, al tener asignadas un total de 4 horas teóricas y 4 horas prácticas, se dispone del tiempo adecuado para llevar a cabo la experimentación docente. En esta unidad, los estudiantes aprenden cómo funciona, se diseña e integra una instalación de agua caliente en un edificio. Los contenidos impartidos se indican en el mapa de contenidos (Figura 1), diferenciando entre los de tipo conceptual (negro), procedimental (naranja) y actitudinal (verde), además de identificar el nivel de profundización teórica en los mismos (ALTO, Medio, Bajo) y las actividades didácticas a realizar (AD), explicadas en el apartado de secuencia de actividades. Los contenidos procedimentales y actitudinales que se movilizan en cada una de las citadas actividades se han indicado mediante unas líneas de color naranja y verde, respectivamente. Estos contenidos pueden ser comunes en varias actividades, pudiendo también una única actividad desarrollar varios contenidos. 
¿Cómo se diseña la instalación de ACS en un edificio?

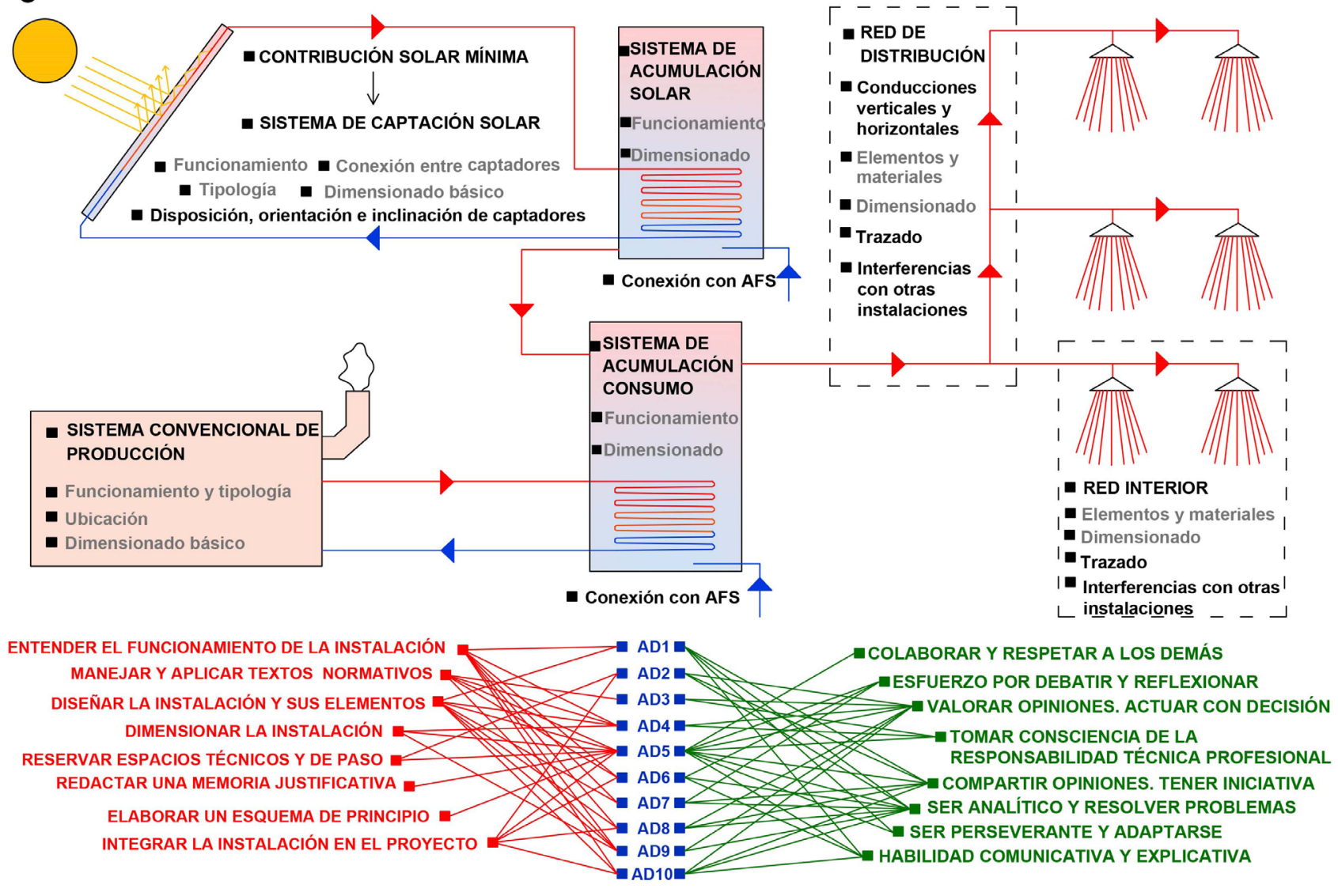

- CONTENIDOS CONCEPTUALES — CONTENIDOS PROCEDIMENTALES I CONTENIDOS ACTITUDINALES

- ACTIVIDADES DIDÁCTICAS (AD)

Nivel de Profundización: ALTO $\longrightarrow$ Medio $\longrightarrow$ Bajo

Figura 1. Mapa de contenidos.

Jornadas de Formación e Innovación Docente del Profesorado I № 2 (2019)

$=0$ Esta obra se distribuye con la licencia Creative Commons

Reconocimiento-NoComercial-SinObraDerivada

4.0

Internacional (CC BY-NC-ND 4.0.) 
El mapa puede leerse de arriba a abajo o viceversa, quedando patente la importancia de la interconexión entre los elementos que integran el sistema. Dada la gran utilidad del dibujo para los arquitectos, a los conceptos de mayor importancia (aquellos que deben preverse en un proyecto de arquitectura desde el momento cero), se les asocia un dibujo: aspectos como la integración de los captadores solares o la localización de los equipos pueden influenciar notablemente la estética de un proyecto, siendo fundamental un adecuado diseño del trazado de la instalación y reserva de espacios técnicos en el proyecto básico. Este mapa permite una representación conceptual de un esquema de principio de la instalación (a nivel de proyecto de ejecución), siendo posible aportar al alumnado las herramientas básicas para que pueda ir completando su aprendizaje.

\section{Secuencia de actividades}

Teniendo como referencia el modelo metodológico expuesto y contemplando los contenidos del mapa, se plantea, concretamente, la siguiente secuencia de actividades didácticas (AD), innovadoras con respecto al sistema tradicional de la asignatura.

$A D$ 1. Cuestionario inicial y fotografiar la instalación de ACS

- Previsión: Tarea no presencial. Semana previa a la primera sesión teórica.

- Descripción: A través de la Plataforma Virtual de la Universidad de Sevilla, se remite a los estudiantes un cuestionario inicial abierto con varias preguntas vinculadas a conceptos clave de la materia ( $\mathrm{Fi}-$ gura 2) y se les solicita que lo cumplimenten siendo lo más sinceros posible. También se les pide que, 
individualmente, hagan fotografías con sus móviles a elementos que crean estar relacionados con la instalación. Se puntualiza que se valorará positivamente la realización de esta actividad voluntaria.

- Sentido formativo: La aplicación de diversas estrategias basadas en la incorporación de las TICS en la enseñanza universitaria debe ser una herramienta más para guiar el aprendizaje (Cacheiro González, 2011), dada la gran componente tecnológica de la sociedad actual. Las herramientas citadas permitirán valorar el nivel de conocimiento inicial del alumnado, sirviendo de punto de partida para un debate reflexivo, previo a la sesión teórica, entre estudiantes-profesora. Al conocer las ideas preconcebidas de los alumnos, será posible encaminar de forma más adecuada el desarrollo de la clase.

1. De los elementos mostrados en las imágenes, ¿cuáles crees que se utilizan para calentar el agua en los edificios? ¿Sabrías decir cómo se llama cada uno de ellos?

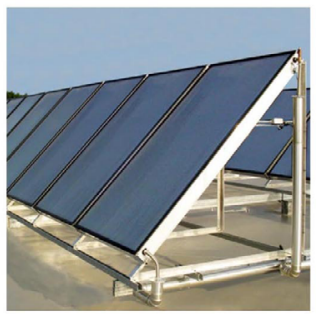

(a)

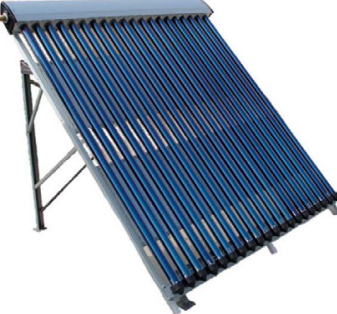

(b)

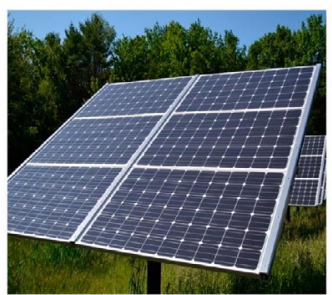

(c)

2. Observa las dos imágenes. ¿Qué diferencias puedes detectar entre los dos elementos? Analiza tanto el tamaño de los equipos, como su ubicación. ¿Crees que se corresponden a un mismo sistema o que son elementos independientes? ¿Por qué? ¿Crees que los dos están en el mismo tipo de edificio? ¿Tienes alguno en tu vivienda?

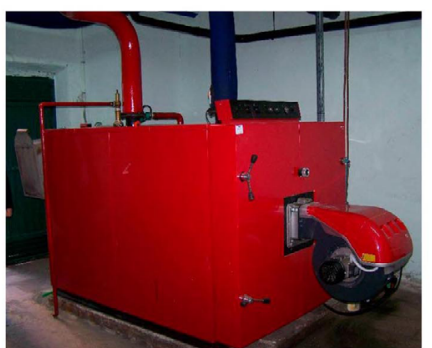

(a)

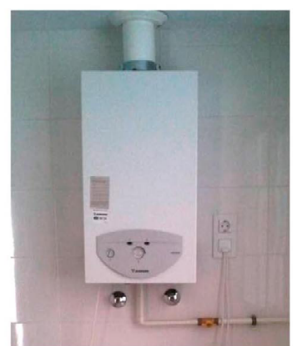

(b)

Jornadas de Formación e Innovación Docente del Profesorado | № 2 (2019) Esta obra se distribuye con la licencia Creative Commons Reconocimiento-NoComercial-SinObraDerivada Internacional (CC BY-NC-ND 4.0.) 
3. Utilizando los conocimientos aprendidos hasta ahora, intenta ordenar de forma lógica los siguientes términos:

$$
\begin{array}{ccc}
\text { PUNTOS DE CONSUMO } & \text { DEPÓSITO ACUMULADOR } & \text { SISTEMA DE APOYO INDIVIDUAL } \\
\text { DEPÓSITO SOLAR } & \text { CAPTADORES SOLARES }
\end{array}
$$

4. Las siguientes imágenes muestran diferentes formas de colocar los paneles solares en un edificio. ¿Qué diferencias ves entre ellas? ¿Crees que la forma de colocar los paneles puede afectar al rendimiento de los mismos? Si es así, ¿en qué medida? De las tres, ¿cuál piensas que es mejor? Argumenta tu respuesta, considerando criterios energéticos y estéticos. ¿Crees que es obligatorio instalar paneles solares?

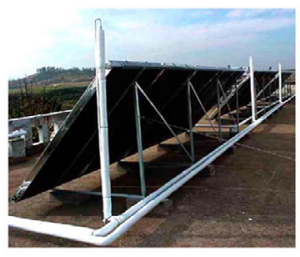

(a)

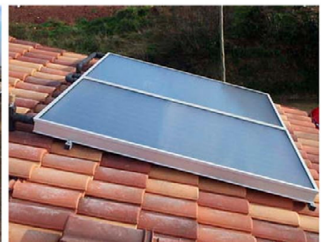

(b)

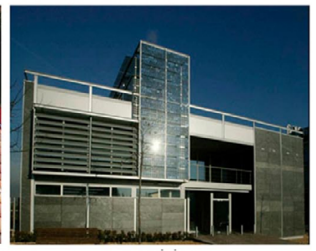

(c)

5. A continuación, se han recogido diversos términos empleados en la instalación de agua caliente de un edificio, clasificándolos en diversas columnas. Mediante el empleo de líneas, intenta relacionar los conceptos entre las columnas. Razona tu respuesta.

$\begin{array}{lccc}\text { Energia solar } & \text { Producción centralizada } & \text { Acumulación individual } & \text { Suministro directo } \\ \text { Energía auxiliar } & \text { Producción individual } & \text { Acumulación mixta } & \text { Suministro indirecto }\end{array}$

Figura 2. Cuestionario inicial.

\section{$A D$ 2. Utilidad de la unidad didáctica}

- Previsión: Como inicio de la primera sesión teórica. 5 min.

- Descripción: Se presenta la unidad didáctica, enmarcándola en la asignatura, con vistas a justificar su impartición y utilidad. Igualmente se realiza un repaso por las capacidades y habilidades que los estudiantes deben adquirir al finalizar esta unidad temática.

- Sentido formativo: Está orientada a crear el interés del alumnado y dar sentido al tema, poniendo énfasis en la aplicación de los conceptos a la vida profesional.

\section{$A D$ 3. Contextualización en el marco normativo}

- Previsión: Tras la actividad previa. 5 min.

- Descripción: Se introduce el tema justificándolo desde el punto de vista normativo, con especial mención del Código Técnico de la Edificación (Ministerio 
de Vivienda de España, 2006). Además, se aportan lecturas recomendadas, webs de casas comerciales y compañías suministradoras, guías técnicas y otros recursos de utilidad.

- Sentido formativo: La regulación normativa es una temática que resulta cuanto menos improductiva a los estudiantes y, en cambio, es vital en la vida real del arquitecto. Esta actividad permite concienciar a los estudiantes de su importancia, proporcionándoles recursos de utilidad para su práctica profesional.

\section{AD 4. Impartición de una base teórica general}

- Previsión: Tras la actividad previa. 2 sesiones: 1 h 30 min. + 1 h 45 min.

- Descripción: En la primera sesión se imparten conceptos básicos, mediante una estrategia pedagógica transmisiva. El análisis de edificios reales se intercala con preguntas a los estudiantes, fomentando su participación. Se explica cómo funciona la instalación, los elementos que la integran y su misión. En la segunda sesión se amplían los conocimientos, desarrollando contenidos más técnicos. Dada la importancia del diseño y trazado de la instalación, se minimiza el cálculo y se potencia el uso de recursos gráficos (esquemas, imágenes, dibujos en la pizarra...).

- Sentido formativo: Dosificar el contenido teórico evita que las sesiones sean abrumadoras para el estudiante, lo que puede llevarle a perder la ilusión por aprender o el interés por la asignatura. El uso de técnicas de expresión gráfica ayuda notablemente a aprehender los conceptos. 
- Previsión: En grupo. En horas no lectivas.

- Descripción: En el modelo, se incluye una componente investigativa, pues, a partir de un ejercicio resuelto facilitado como ejemplo, los estudiantes deben resolver esta instalación en dos edificios reales, debiendo usar las herramientas proporcionadas en las actividades 3 y 4 . Se escogen dos edificios para trabajar las diferencias normativas, desde diferentes escalas: conjunto (conexión con red urbana), bloque (red común) y unidad (red interior).

- Sentido formativo: El objetivo inmediato es poner en práctica los conceptos aprendidos. El trabajo en grupo aporta las habilidades necesarias para participar en equipos disciplinares en su vida profesional. La aproximación por escalas permite aprender cómo se relacionan los elementos de la instalación entre sí.

\section{$A D$ 6. Exposición pública y debate reflexivo}

- Previsión: 2 sesiones: $2 \mathrm{~h}+1 \mathrm{~h} 15 \mathrm{~min}$.

- Descripción: La actividad anterior se comenta y debate en clase de forma expositiva. Los grupos, por turno, deben explicar los avances realizados en la elaboración del ejercicio, las decisiones que han tomado, los problemas que les hayan surgido o las dudas que tengan al respecto. El debate se entiende no solo entre estudiantes-profesora, sino también entre estudiantes-estudiantes, completando la metodología con la parte "social" de la experiencia (Finkel, 2008).

- Sentido formativo: Esta actividad simplifica el tiempo dedicado a la resolución de dudas comunes, además de permitir descubrir otras propuestas o soluciones planteadas por compañeros de clase. Se completa el contenido teórico, aclarando o ampliando conceptos, de forma que sea posible hilar teoría y práctica. 
- Previsión: De forma individual. 15 min. tras la segunda sesión teórica.

- Descripción: Se les facilita un ejercicio consistente en un esquema de principio de esta instalación (Figura 3), que deben completar con información básica sobre la terminología técnica. También deben detectar y resolver algunos errores del mismo.

- Sentido formativo: Este tipo de planteamiento ayuda a que los estudiantes presten más atención a lo que hacen para no equivocarse y afiancen así sus conocimientos.

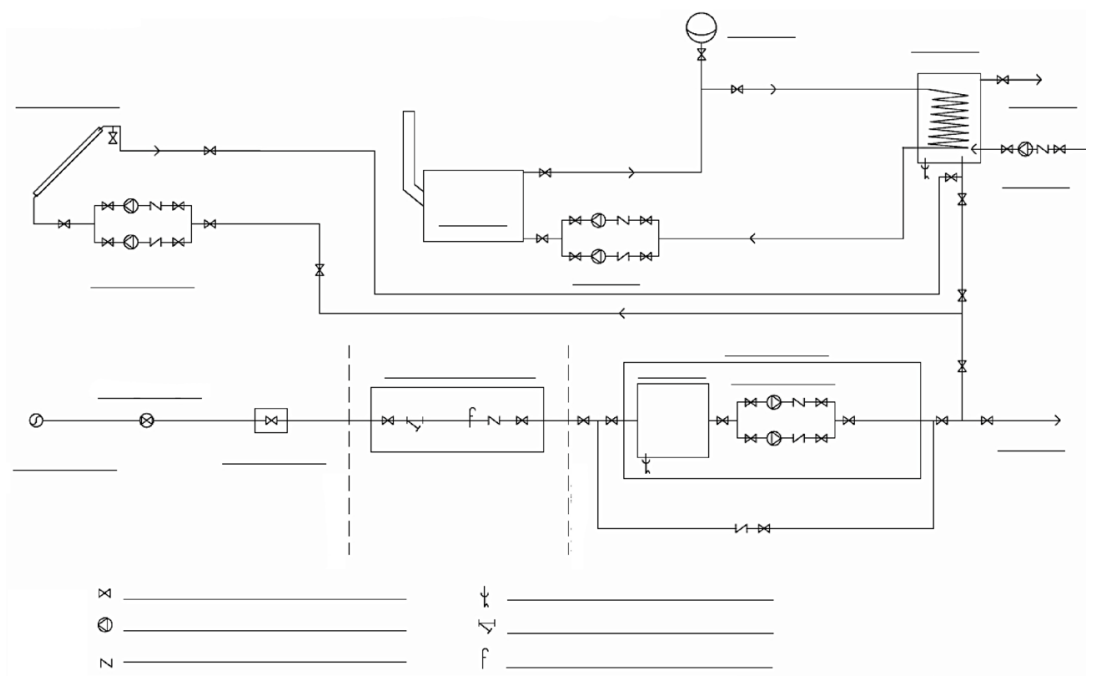

Figura 3. Ejercicio para pensar.

$A D$ 8. Realizar un cuestionario en tiempo real con el móvil

- Previsión: De forma individual. 15 min. tras la segunda sesión teórica.

- Descripción: Se les pide a los estudiantes que completen, en tiempo real y con sus móviles, un cuestionario online (Figura 4) mediante una aplicación móvil (Socrative, 2013). 
- Sentido formativo: Este cuestionario permite evaluar, de forma anónima, el nivel de conocimientos adquiridos. Si fuera necesario, se podría re-iniciar el proceso pedagógico, reforzando aquellos aspectos impartidos que no hayan quedado claros.

\section{$A D$ 9. Elaboración de preguntas para la prueba de nivel}

- Previsión: Tarea no presencial. Debate de 15 min. tras la segunda sesión teórica.

- Descripción: Se propone a los estudiantes que, individualmente, preparen al menos una pregunta tipo test, remitiéndola por la Plataforma Virtual. Tras hacer una selección de las de mayor interés, se debaten en la clase siguiente.

- Sentido formativo: Con ello, se obliga a los estudiantes a estudiar sus apuntes, atrayéndolos hacia el razonamiento disciplinar. Las preguntas bien elaboradas y formuladas pueden ser incluidas en la prueba de conocimientos (prueba de nivel) de la asignatura, obligatoria de acuerdo al Programa Docente, motivando así al alumnado.

\section{$A D$ 10. Cuestionario final}

- Previsión: 15 min. tras la segunda sesión teórica.

- Descripción: Se entrega el cuestionario final, con el mismo contenido que el inicial, pero con preguntas más focalizadas al temario, guiando sus respuestas al uso del lenguaje técnico.

- Sentido formativo: Tras su comparación con el inicial, se valorará la evolución académica y la trayectoria crítico-analítica del alumnado, una vez desarrollado el tema. 
1. Te han encargado el diseño de una instalación de ACS en una vivienda de un bloque, y decides incluir un intercambiador de calor como el de la imagen. ¿Qué debes tener encuenta de las siguientes afirmaciones?

(A) Falta la tubería de retorno invertido

(B) Todas las tuberías deberían ir calorifugadas

(C) Se dispone antes de la caldera de la vivienda

(D) El consumo de agua caliente es comunitario

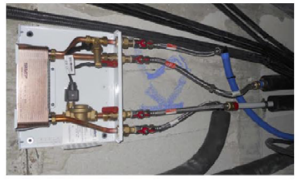

2. En el portal de entrada de un edificio de viviendas, el fontanero va a incluir un elemento como el de la imagen. ¿Cuál de las siguientes afirmaciones que te dice no es incorrecta?

(A) Se ven dos contadores de agua: uno de agua fría y otro de agua caliente.

(B) Son dos llaves de compuerta de la arqueta de acometida.

(C) Son dos contadores de agua fría, probablemente de dos portales.

D Son dos contadores de agua caliente, probalemente de dos portales.

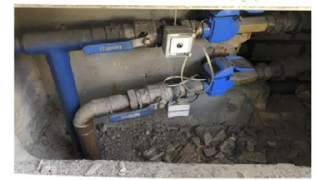

3. Estás pensando en incluir un sistema de producción auxiliar en tu vivienda, pero no sabes cuál y ves esto (imagen) en casa de tu compañero. ¿Qué opción es la correcta?

(A) Es una caldera estándar utilizada como sistema de apoyo auxiliar para la producción de ACS.

(B) Probablemente se trate de un sistema de producción centralizada y de acumulación individual.

C Es un depósito acumulador para la producción de ACS de una vivienda.

D Es un sistema obsoleto, concretamente una caldera atmosférica, pues la extracción de humos es horizontal hasta el patio.

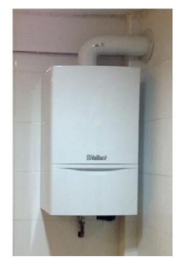

4. En la imagen se ven dos elementos de color rojo. ¿Qué son?

A Son depósitos acumuladores donse se puede almacenar ACS para consumo.

B Son dos purgadores: permiten expulsar el aire que pueda haber en las tuberías.

C Son dos vasos de expasión: el más grande es del circuito primario y, el otro del secundario.

D Son dos intercambiadores: permiten intercambiar calor entre dos circuitos diferentes sin mezclar los fluidos.

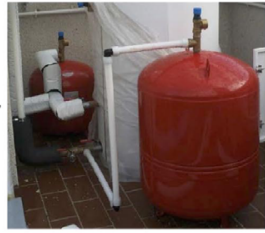

5. ¿Cuáles de las siguientes afirmaciones no es correcta en relación a las bombas que se muestran en la imagen?

(A) Se instalan en serie para aprovechar la potencia de las dos

(B) Se deben disponer en los circuitos cerrados para mover el agua.

(C) Se utilizan en los circuitos de retorno para mover el agua.

(D) Se instalan en paralelo y al menos una de ellas debe estar en reserva.

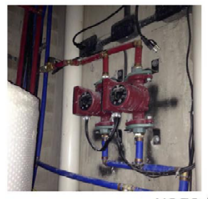

rage 1 of

6. En el edificio de viviendas que estás proyectando debes incluir captadores solares. ¿Cuál de las siguientes afirmaciones que te explica tu amigo, vendedor de captadores solares, es la correcta?

A Los captadores solares son elementos de producción de ACS y forman parte del circuito primario de la red.

B Los captadores solares para producción de ACS deben instalarse obligatoriamente en la cubierta del edificio.

C Los captadores solares mostrados en la imagen tienen mayor rendimiento que los de tubo de vacio.

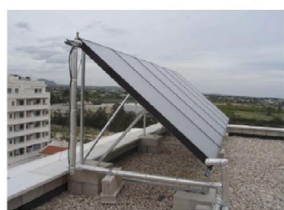

D Los valores de pérdidas límite por orientación e inclinación establecidos en el HE4 del CTE para estos captadores, son menos restrictivos que los exigidos para los superpuestos en cubiertas inclinadas.

Figura 4. Cuestionario Socrative. En amarillo se ha indicado las respuestas correctas.

Jornadas de Formación e Innovación Docente del Profesorado I № 2 (2019) Esta obra se distribuye con la licencia Creative Commons Reconocimiento-NoComercial-SinObraDerivada Internacional (CC BY-NC-ND 4.0.) 


\section{Aplicación del Ciclo de Mejora en el Aula}

La AD 1 fue bastante grata, con un gran número de alumnos que participaron en el envío de imágenes. Algunas me parecieron bastante interesantes, lo que me permitió iniciar en clase un atractivo debate. Con ello, pude observar que los estudiantes mostraban más interés por el tema debatido. En cambio, durante la elaboración del cuestionario inicial por parte de los alumnos, sentí que era bastante complicado recibir respuestas sinceras y completas, pues me dio la sensación de que no se lo tomaban con la seriedad que yo había esperado.

Con la AD 2 fue posible captar la atención del alumnado, pues muchos de ellos comprendieron que no iba a ser una asignatura fundamentalmente de cálculo, como en un primer momento se habían imaginado. Al darle mucha más importancia a aspectos como el diseño y la integración de la instalación en el proyecto arquitectónico frente al dimensionamiento de la misma, pude llegar a ver algunas caras de asombro.

Seguidamente, con la AD 3, muchos alumnos comprendieron la importancia de las normas de cara a proponer soluciones adecuadas y viables para el desarrollo de la instalación. Algunos mostraron cierta soltura en la labor de búsqueda e interpretación del articulado normativo durante el ejercicio, pero este número de alumnos fue bastante reducido. Hubo bastantes momentos en los que sentí frustración, especialmente durante las sesiones prácticas, pues alumnos concretos mostraban una actitud totalmente pasiva. Ellos mismos reconocían la importancia de la normativa, pero me confesaban no haber consultado los breves textos normativos que les había facilitado. En consecuencia, pienso que es necesario darle un nuevo enfoque a esta actividad, tal vez ligándola más aún a la parte práctica. 
Un aspecto que me pareció bastante significativo fue la reacción de los alumnos al uso que yo hacía de la pizarra durante la $A D$ 4. Esto hizo que los estudiantes tomasen más apuntes de lo esperado, dado que entendían que lo que se dibujaba en la pizarra no formaba parte del contenido que se les había facilitado mediante los apuntes de clase. Además, como los cuestionarios iniciales que habían hecho incluían imágenes extraídas del propio tema, creí oportuno comentarlas a medida que iban apareciendo. Esto fue bastante entretenido, tanto para mí como para ellos, quienes aportaban reflexiones muy positivas. Esta parte de la clase me pareció bastante amena para los estudiantes, pues algunos llegaron a hacerme preguntas más concretas para profundizar en los contenidos que estábamos viendo. Desde mi punto de vista, otro aspecto muy destacable, que fue bastante productivo para los alumnos, fue realizar una sintesis de las conclusiones más relevantes al final de las sesiones.

En relación a la $A D 5$, aunque sea un ejercicio que se resuelve por grupos, me pareció que podría ser más instructivo y didáctico el que a cada grupo le asignase unas condiciones de partida diferentes. De esta forma, se plantearon escenarios diversos que exigían aproximaciones concretas, nutriendo en mayor medida los debates y las exposiciones. Este hecho tuvo la acogida que esperaba entre los alumnos, pues todos coincidieron en que habían aprendido mucho trabajando desde hipótesis reales. Además, al tener cada grupo unas hipótesis diferentes, eliminé la posibilidad de que copiasen las soluciones de un grupo a otro, por lo que noté que, al menos los alumnos más interesados por la mecánica de trabajo, también estaban más atentos durante la AD 6.

En esta última actividad (AD6), para evitar un debate profesora-alumnos muy monótono, decidí pedir a los alumnos que, al menos por grupo, tomasen anotaciones y apuntasen preguntas sobre la exposición de sus compañeros, 
debiendo ellos mismos iniciar posteriormente un debate. Reconozco que, al ser la primera vez que planteaba esto en clase, el inicio del debate fue de baja intensidad y poca participación, lo que me preocupó un poco. Pero gracias a que algunos alumnos se iban animando poco a poco, fueron arrastrando con ellos la participación del resto de sus compañeros, incluso pude ver que algunos de ellos se alentaban entre sí. Debo reconocer que esta actividad dio muy buenos resultados, pero también siento que fue una labor colaborativa entre profesora y alumnos. El debate se convirtió en algo más que una mera corrección, pues los estudiantes comenzaron a coger soltura en la explicación de las decisiones tomadas, las dificultades encontradas y las respuestas dadas en base a la normativa.

Con la AD 7 les ayudé a asimilar conceptos, profundizando en aspectos de mayor relevancia y aclarando algunas dudas. En clase, le dedicamos unos minutos a resolver este ejercicio. Empecé preguntándoles a ellos y me sorprendí gratamente cuando me di cuenta de que se estaban contestando los unos a los otros, corrigiéndose entre ellos, siendo mi intervención bastante puntual. Ellos mismos me agradecieron mucho esta actividad, pidiéndome más tareas similares, pues admitieron haberlo "pasado bien aprendiendo". Que ellos me dijeran eso me alegró muchísimo e hizo que me involucrase todavía más en las siguientes actividades.

Mientras completaban el cuestionario de la AD 8, mostré en tiempo real los aciertos y errores de los encuestados "anónimos", encontrando reacciones muy diversas: seriedad, concentración, agobio... Algunos estaban disfrutando bastante con los resultados mostrados en pantalla. Otros admitieron haberse equivocado bastante y querían intentarlo de nuevo. Cuando todos lo completaron, analizamos los resultados y los debatimos en clase. Durante esta actividad, observé que muchos de ellos estaban atentos a lo que íbamos diciendo, incluso estudiantes que no 
se habían involucrado mucho antes. En general, debo reconocer que esta actividad fue también muy bien recibida entre los alumnos.

Cerca de la mitad de la clase me envió las preguntas de la AD 9, gracias a lo cual les obligué, al menos a esos estudiantes, a que revisaran sus apuntes. Tras seleccionar algunas de esas preguntas que me parecieron más sugerentes, las comenté con ellos en clase. Sin dar los resultados en un primer momento, ellos mismos iban contestando a las preguntas, algunos se equivocan, otros acertaban. Les observé detenidamente y vi reacciones curiosas: cuando sus compañeros acertaban, ellos intentaban acertar la siguiente pregunta, algunos incluso competían dentro de los grupos de clase. El ambiente fue una mezcla de entretenimiento y concentración, lo que me dio la impresión de que fue una de las actividades clave del ciclo de mejora. Dada las buenas reacciones de los alumnos y la satisfacción que sentí al finalizar esta actividad, creo adecuado mantenerla en mi práctica docente habitual.

Como última actividad del ciclo de mejora, el cuestionario final de la $A D 10$ lo realizaron los alumnos con mayor seriedad. A medida que lo entregaban, comprobé que muchos habían escrito bastante, incluso utilizando los márgenes del papel, a diferencia de lo sucedido en el cuestionario inicial, en el dejaron preguntas en blanco. He de reconocer que esto hizo que me sintiera un poco orgullosa de los logros que había conseguido. Aunque no sabía todavía los resultados de los cuestionarios, había podido ver cómo algunos estudiantes habían progresado desde el inicio del curso, participando más activamente en clase.

\section{Evaluación del aprendizaje de los estudiantes}

Al finalizar el ciclo docente, se ha evaluado el aprendizaje alcanzado por el alumnado a partir de la comparación 
de los resultados de los cuestionarios inicial y final. Dado el carácter abierto de las preguntas, se ha recurrido al análisis empírico y clasificación de las respuestas proporcionadas, definiendo para ello unos escalones de aprendizaje específicos para cada pregunta, siguiendo los criterios recomendados por Rivero y Porlán (2017).

La Figura 5 muestra los resultados iniciales y finales de los cuestionarios, aportando los valores medios en la clase. Puede observarse que el aprendizaje de los estudiantes ha mejorado un escalón de media (véase en Figura 6), prácticamente de un conocimiento medio en el nivel $D$ hasta el C, que como media en puntos del 1 al 5 ha pasado de 1,99 en el cuestionario inicial a 3,39 en el final (" $X$ " en el diagrama de caja y bigotes). Pese a haber respuestas muy brillantes, son bastante puntuales. De forma excepcional, en una de las preguntas del cuestionario los estudiantes han llegado a subir hasta dos e, incluso, tres escalones, para ubicarse, en más de un 50\% de la clase, en el nivel B. El motivo de esta puntuación tan alta se debe a la mayor relación de esa pregunta con otras actividades trabajadas durante el ciclo de mejora, por lo que los estudiantes han afianzado más sus conocimientos.

\section{VALORACIÓN MEDIA DEL ALUMNADO}
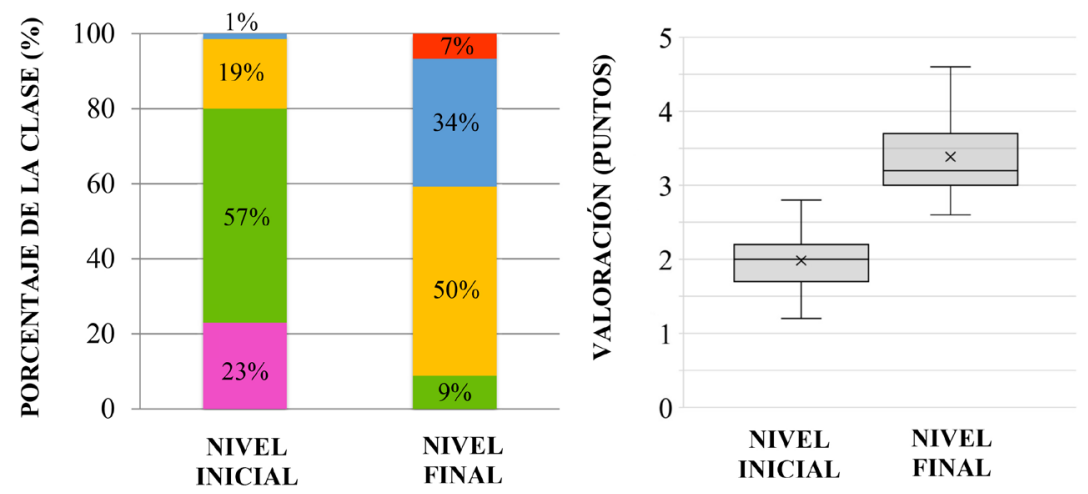

A (5 puntos) $\quad \mathrm{B}(4$ puntos) $\quad \mathrm{C}(3$ puntos $) \quad \square$ D (2 puntos $) \quad \mathrm{E}(1$ punto)

Figura 5. Comparación de los resultados de los cuestionarios inicial y final. 


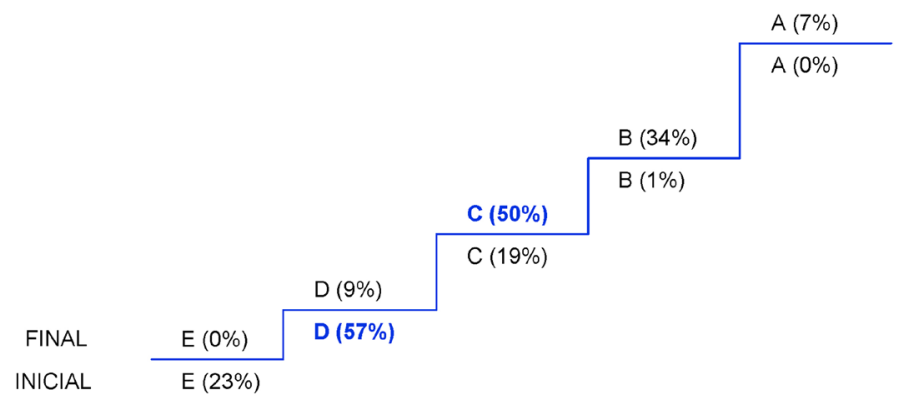

Figura 6. Escaleras de aprendizaje inicial y final.

En definitiva, puede verse que el progreso ha sido bastante positivo, pues todos los estudiantes han sobrepasado la media de los 2,5 puntos (la mitad de la puntuación total). No obstante, si se comparan estos resultados con los obtenidos del cuestionario cerrado realizado en la actividad 8, mediante la aplicación móvil Socrative, se puede observar que éstos últimos han sido mejores, dado que no había que explicar la respuesta dada (Figura 7).

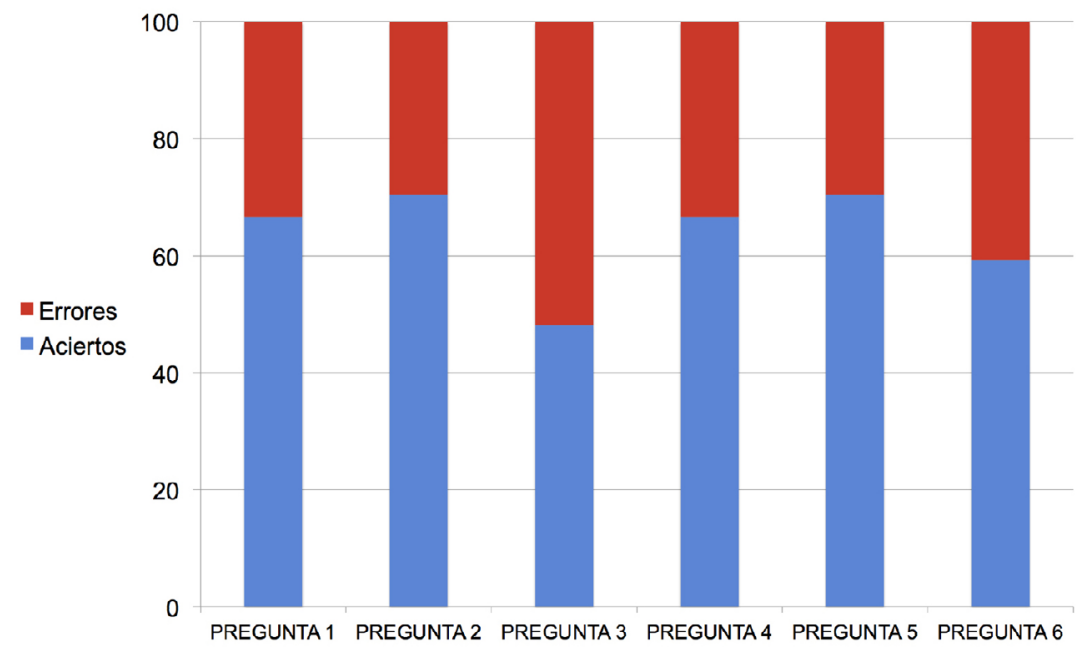

Figura 7. Resultados del cuestionario Socrative.

Jornadas de Formación e Innovación Docente del Profesorado | № 2 (2019) Esta obra se distribuye con la licencia Creative Commons Reconocimiento-NoComercial-SinObraDerivada 


\section{Evaluación del Ciclo de Mejora en el Aula}

Aunque la valoración del desarrollo del ciclo de mejora puede ser realizada desde diversas perspectivas, fundamentalmente se pueden destacar los siguientes objetivos alcanzados:

- Se ha conseguido despertar y elevar el grado de motivación del alumnado en la adquisición de competencias relacionadas con la materia, dado que se incorporan de forma directa herramientas que manejan en el día a día.

- Se ha conseguido una mejora en los resultados académicos de los estudiantes tras la valoración del aprendizaje mediante los cuestionarios inicial y final.

- Se han logrado resultados materiales (la serie de fotografias, las preguntas...), que pueden convertirse en material didáctico e, incluso, ser expuestos en la Plataforma Virtual de la asignatura para dar soporte pedagógico a los propios estudiantes, a modo de intercambio entre ellos mismos y con los de cursos sucesivos.

- El trabajo en equipo ha favorecido la puesta en común y las reflexiones críticas mediante los debates han fomentado la participación de los estudiantes, animándoles a ser los protagonistas del discurso, perdiendo la timidez inicial de hablar en público.

- En los momentos más brillantes, los alumnos han sido capaces de dirigir y orientar la sesión, aprendiendo de sus compañeros y creando un ambiente de trabajo satisfactorio.

En definitiva, la experiencia del ciclo de mejora docente ha sido significativamente satisfactoria, aunque ha habido algunos aspectos que deben ser puntualizados. Pese a que los resultados obtenidos en los cuestionarios reflejan una mejora del aprendizaje de la clase de un escalón de media, las respuestas brillantes son bastante puntuales y, en general, los estudiantes muestran dificultades 
importantes a la hora de justificar y razonar las respuestas. Este hecho queda patente al comparar los resultados de los cuestionarios abiertos con el cuestionario cerrado de la actividad 8 (Socrative), donde los niveles han sido mejores.

Por otro lado, las actividades 6 (Exposición pública y debate reflexivo), 7 (Ejercicio para pensar) y 9 (Elaboración de preguntas para la prueba de nivel) han sido muy bien recibidas entre los estudiantes, teniendo una repercusión positiva indirecta en los cuestionarios finales. Por este motivo, parece coherente aplicarlas con mayor frecuencia en la práctica docente habitual. Siguiendo el planteamiento de K. Bain (2004), los principios didácticos buscados con esta experiencia, e incorporados para el futuro, han sido: promover el interés y el aprendizaje activo, ser conscientes de los modelos mentales del alumnado antes de iniciar las tareas docentes, fomentar el uso de mapas de contenidos como herramienta de mejora, atraerlos al razonamiento disciplinar y emplear estrategias de evaluación del aprendizaje.

Jornadas de Formación e Innovación Docente del Profesorado | № 2 (2019) Esta obra se distribuye con la licencia Creative Commons 


\section{Referencias bibliográficas}

Bain, K. (2004). Lo que hacen los mejores profesores universitarios. Publicacions de la Universitat de València.

Cacheiro Gonzalez, M.L. (2011). Recursos educativos TIC de informacion, colaboracion y aprendizaje. Pixel-Bit. Revista de Medios y Educacion, 39, 69-81.

Finkel, D. (2008). Dar clase con la boca cerrada. Valencia: Publicacions de la Universitat de València.

Socrative (2013). Socrative mobile application software. Disponible en: http:// socrative.com

Ministerio de Vivienda de España (2016). Real Decreto 314/2016, de 17 de marzo. Código Técnico de la Edificación. Madrid.

Mora, F. (2013). Neuroeducación: solo se puede aprender aquello que se ama. Madrid: Alianza.

Rivero, A. y Porlán R. (2017). La evaluación en la enseñanza universitaria. En R. Porlán (Coord.), Enseñanza Universitaria. Cómo mejorarla (pp. 73-91). Madrid: Morata.

Jornadas de Formación e Innovación Docente del Profesorado | № 2 (2019) Esta obra se distribuye con la licencia Creative Commons Reconocimiento-NoComercial-SinObraDerivada 4.0 Internacional (CC BY-NC-ND 4.0.) 